\title{
The relative strengths of debris-laden basal ice and clean glacier ice: some evidence from Taylor Glacier, Antarctica
}

\author{
WENDY LAWSON \\ Department of Geography, University of Canterbury, Christchurch, New Zealand
}

\begin{abstract}
An understanding of the mechanical behaviour of the basal zone of an ice mass is fundamental to understanding the overall dynamics of that ice mass. Despite the fact that debris-laden ice is found in the basal zones of many glaciers and ice sheets, its mechanical behaviour is only poorly understood. This paper attempts to expand our knowledge of the mechanical behaviour of debris-laden ice by examining the uniaxial compressive strength of debris-laden basal ice sampled from the snout of the Taylor Glacier, Antarctica.

The mechanical behaviour of debris-laden ice (debris content $5-20 \%$ by volume) under uniaxial compression, and the relationship between the behaviours of debrisladen basal ice and 'clean' glacier ice, is complex and variable. At the relatively warm temperatures at which uniaxial compressive strength tests were conducted in the field, debris-laden ice was generally weaker than clean glacier ice. At these temperatures, between $0^{\circ}$ and $-5^{\circ} \mathrm{C}$, pressure melting was the dominant deformation mechanism in the debris-laden ice and cracking the dominant deformation mechanism in clean ice. At $-25^{\circ} \mathrm{C}$, however, debris-laden ice reached higher strengths than the clean glacier ice and cracking was the dominant deformation mechanism in both ice types. The change in relationship between the strengths of debris-laden and clean ice with temperature is inferred to be attributable to the temperature dependence of the rate of pressure melting.

These results suggest that the dynamic effects and significance of the presence of a debris-laden ice layer in the basal zone of an ice mass are likely to be highly variable in space and time.
\end{abstract}

\section{CONTEXT AND AIMS}

The issue of the mechanical behaviour of debris-laden ice is highly significant for ice sheet modelling, since it pertains to the state of the basal boundary condition. Clearly, in order to model effectively the past, present and future behaviour of ice sheets, modellers need to include a realistic parameterization of the basal boundary condition in their models. At present, however, most attention is directed towards details of the parameterization of the upper surface boundary condition. This imbalance is at least partly a function of the ongoing uncertainties surrounding both the nature and behaviour of the basal boundary. This paper aims to contribute to a furthered understanding of the mechanical characteristics of one possible basal boundary configuration, by exploring the behaviour of debris-laden ice.

Previous work on the mechanical behaviour of debrisladen ice has produced diverse and apparently contradictory conclusions. On the one hand, workers conducting laboratory experiments on laboratory-produced debris-laden ice (Hooke and others, 1972; Nickling and Bennett, 1984) have concluded that the presence of debris strengthens ice, a phenomenon that Hooke and others attributed to inhibition of dislocation motion by the physical presence of solid particles. On the other hand, structural field observations (Echelmeyer and Zongxiang, 1987; Lawson, 1989) and experiments on samples from ice-sheet cores (Shoji and Langway, 1984; Fisher and Koerner, 1986) have indicated that debris-laden ice is weaker than contiguous clean ice. The workers on debrisladen ice from ice sheets have generally attributed the contrast in behaviour not directly to the presence of the debris but to variation of ice crystal fabric and texture characteristics.

The various works outlined above are clearly not directly comparable, because they explore the issue of the strength of debris-laden ice from a range of perspectives using various methods. However, the apparent contradictions between their conclusions point to the importance of the subject matter of this paper. The importance of the issue of the relative strengths of debris-laden and clean ice lies in the possible dynamic effects of the presence of a debris-bearing layer at the base of an ice mass. If debris increases the strength of ice, then a debrisbearing layer in the basal zone will act as a retardant to motion, whilst if debris decreases the strength of ice, a basal debris-bearing layer will in effect act as a lubricant. Where modellers have attempted to factor in the effects of the presence of a rheologically different layer at the base of an ice mass, they have generally assumed that the basal layer will be softer than the overlying ice (e.g. Reeh and 
Paterson, 1988). It is clear that the presence of a rheologically different layer at the base of an ice mass will have a major effect not only on the dynamics of an ice mass but also on its morphology and extent (Beget, 1986). This issue is therefore of fundamental importance to modellers.

The overall aim of this paper, then, is to elucidate the relative mechanical behaviours of debris-laden and clean glacier ice sampled contiguously from the same glacier, in order to shed some light on the problem outlined above. The parameter of mechanical behaviour used for this comparison is the unconfined uniaxial compressive strength (UCS) in rapid loading of cylindrical ice samples. This parameter was chosen because it is readily measurable in field conditions and therefore suited to the field orientation of this research. It is also rapidly measurable and thus conducive to the accumulation of a representative data set. In addition, UCS is a unique single measure of the behaviour of a sample and therefore useful for the development of the comparative data sets required here. Experiments were necessarily conducted at high strain rates (see discussion in "Procedure"), in order to ensure the failure necessary for the establishment of UCS. High strain rates also facilitated the collection of a large number of data.

In the context of the overall aim and the selected mechanical parameter, the specific aims of the paper are: (1) to compare the unconfined uniaxial compressive strength (UCS) of debris-laden and clean ice samples over a range of temperatures and (2) to compare qualitative aspects of the behaviours of the two ice types during deformation and failure.

This paper provides a comparative study of the net differences in behaviour between groups of samples of two ice types rather than of differences between individual samples. The bulk sedimentological and ice texture characteristics of the two ice types are summarized in the next section.

\section{THE FIELD SITE: TAYLOR GLACIER}

Taylor Glacier is a $90 \mathrm{~km}$ long, easterly flowing outlet of the East Antarctic ice sheet in the Dry Valleys area of Antarctica. Taylor Glacier was chosen for this research because its snout area has a very distinctive sequence of debris-laden basal ice clearly exposed and readily accessible around approximately $4 \mathrm{~km}$ of the terminus (Fig. 1). This debris-bearing layer has been the subject of a previous detailed study (Robinson, 1979), which together with observations from the present work provides the following summary of the bulk characteristics of the debris-laden and clean ice types. Field icefabric analyses were planned as part of the current study but were impossible in the event due to warm ambient temperatures. As a result, no fabric information is available for either ice type.

This debris-laden basal ice layer of Taylor Glacier, from which debris-laden ice samples were taken for this work, is up to $5 \mathrm{~m}$ thick and comprises a range of debrisladen ice facies, including laminated, dispersed and massive debris-laden ice (see classification of Hubbard and Sharp (1995)). The debris content of this ice ranges
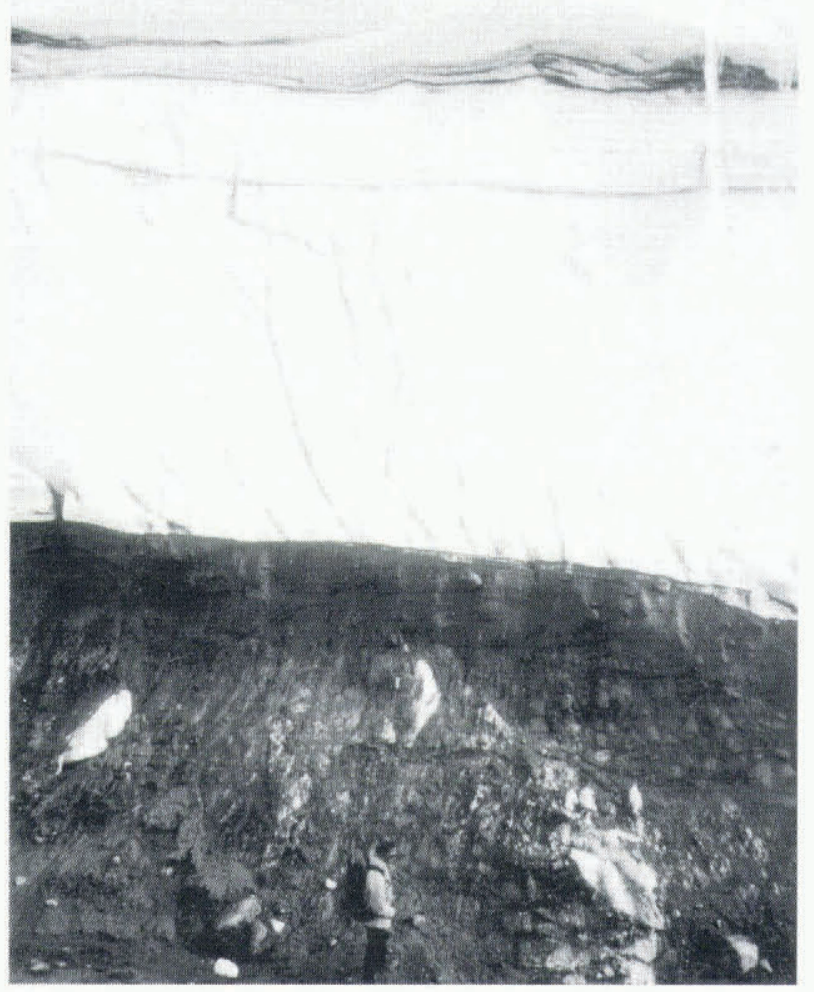

Fig. 1. The ice margin in the terminus area of Taylor Glacier, showing the distinctive debris-laden basal ice layer exposed at the foot of a vertical ice cliff.

from less than $1 \%$ to greater than $50 \%$ by volume and the debris is predominantly sand-sized (sand fraction $>50 \%$ by weight). Ice crystallographic work by Robinson (1979) suggests that the ice crystals in the debrisbearing basal layer are coarser than those in the overlying clean glacier ice layer, although this finding is not considered to be very reliable.

The clean glacier ice overlying the basal layer, and comprising the bulk of the glacier's volume, has less than $1 \%$ by volume debris content. Robinson's (1979) work indicated that the ice texture may be finer than the debris-laden ice but, as indicated above, this finding may be unreliable.

\section{PROCEDURE}

UCS testing requires cylindrical samples with a length-towidth ratio $\geq 2$ (Brown, 1981). Ice samples meeting these criteria were obtained from Taylor Glacier using handheld drilling equipment, consisting of a chainsaw fitted with an off-the-shelf rotary adaptor. Drilling with this equipment was constrained to vertical sampling, since sufficient pressure could only be applied with the axis of the apparatus upright. This equipment was portable, inexpensive, did not require drilling lubricant and was highly successful in use. Specially designed diamondtipped bits were used for obtaining debris-laden ice samples and saw-tooth drill bits for clean ice samples. 
These bits were designed with an internal diameter of $63 \mathrm{~mm}$ (a standard of geomechanical testing) and produced samples with a diameter of approximately $60 \mathrm{~mm}$. The raw samples were prepared for testing by smoothing their end surfaces with a handsaw and/or by rapid melting on a hot plate. In addition, load was applied slowly during the initial moments of each test in order for pressure melting to complete the smoothing of the end surfaces and thus to allow the load to be evenly distributed through the cross-section. The loading conditions were not, therefore, precisely constrained but are considered to be sufficiently constrained to support the comparative inferences intended here.

Debris-laden and clean ice samples were obtained from marginal ice at several sites in the snout area of the glacier. Weathered surface ice was removed prior to sampling. Samples were taken within $1 \mathrm{~m}$ vertical distance of the debris-laden/clean ice contact (see Fig. 1). Each sample was obtained with its axis as close as possible to orthogonal to any ice layering, although this criterion was secondary to the need to drill vertically, as outlined above.

The overall procedure for UCS testing of a material involves the axial loading of a cylindrical sample until failure occurs, i.e. until no further load can be supported and the sample de-stresses. The UCS is calculated from the maximum measured stress during the test, which is an index of the maximum strength of the sample during the experiment. For this work, a commercially available fieldloading device designed for point-load testing was adapted for UCS testing by the substitution of steel platens for the points (Fig. 2). This device was a hardloading machine, in which a strain was applied by the manual operation of an hydraulic pump and a stress produced as a result. The stress was displayed in real time on an LCD and also output at $0.25 \mathrm{~s}$ intervals to a data logger. The hydraulic pump was operated in such a way as to obtain as constant a strain rate as possible, both through individual tests and between tests. Most tests required more than one stroke of the pump before failure and these samples were therefore de-stressed during the off-stroke. Stress strain curves for the experiments in which this de-stressing was necessary indicate that stress was recovered during subsequent strain. This testing apparatus was used successfully in all experiments and required no adaptations for use in cold-laboratory conditions.

Most of the UCS testing programme was carried out in the field, adjacent to the sampling site and as soon as possible after sampling, in order to minimize the effects of transport of the ice and therefore to obtain results as close as possible to those which would be obtained were it possible to test the ice in situ. Laboratory tests were also carried out, at $-5^{\circ},-15^{\circ}$ and $-25^{\circ} \mathrm{C}$, in order to investigate the effect of temperature. Ice was stored and transported where necessary in insulated containers and tested as soon as possible after sampling. Field testing was generally conducted within 2-3hours of sampling. Laboratory testing was conducted up to 5 days after sampling. Samples tested in the laboratory were allowed to equilibrate with the ambient temperature of the cold room for at least 24 hours prior to testing.

In field tests, the temperature of each debris-laden ice

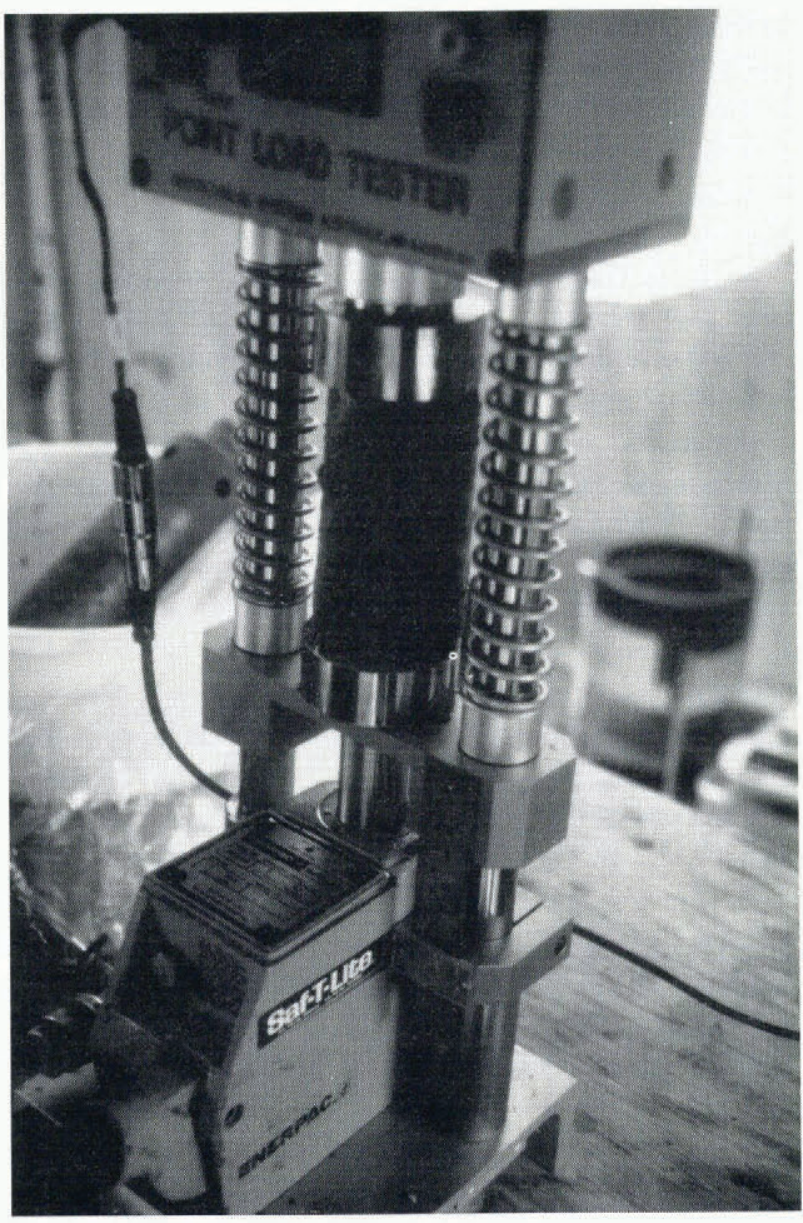

Fig. 2. Apparatus used for field and laboratory testing of unconfined uniaxial compressive strength of ice samples.

sample was measured after testing by the insertion of a temperature probe into a small hole drilled into the sample with a hand drill. Clean ice samples almost always disintegrated after testing and it was not therefore possible to obtain a useful indication of their temperature.

Tests were conducted at strain rates in the range $10^{-2}-10^{-3} \mathrm{~s}^{-1}$. These strain rates are $2-3$ orders of magnitude greater than would occur in most naturally deforming ice bodies. Total strains during testing were 3 $15 \%$, with smaller total strains occurring at colder temperatures. The duration of tests ranged from a few seconds to longer than a minute. Post-test temperatures of debris-laden ice samples ranged from just below $0^{\circ}$ $\left(-0.1^{\circ} \mathrm{C}\right)$ to $-3.4^{\circ} \mathrm{C}$.

Table 1. Mean UCS (MPa) for debris-laden and clean ice samples from Taylor Glacier. Sample size $n$ is indicated in parentheses

\section{Testing environment Debris-laden ice Clean ice}

$\begin{array}{rll}\text { Field } & 1.1(101) & 2.7(110) \\ -5^{\circ} \mathrm{C} & 3.7(14) & 3.4(10) \\ -15^{\circ} \mathrm{C} & 6.2(16) & 1.9(12) \\ -25^{\circ} \mathrm{C} & 7.6(15) & 3.0(15)\end{array}$




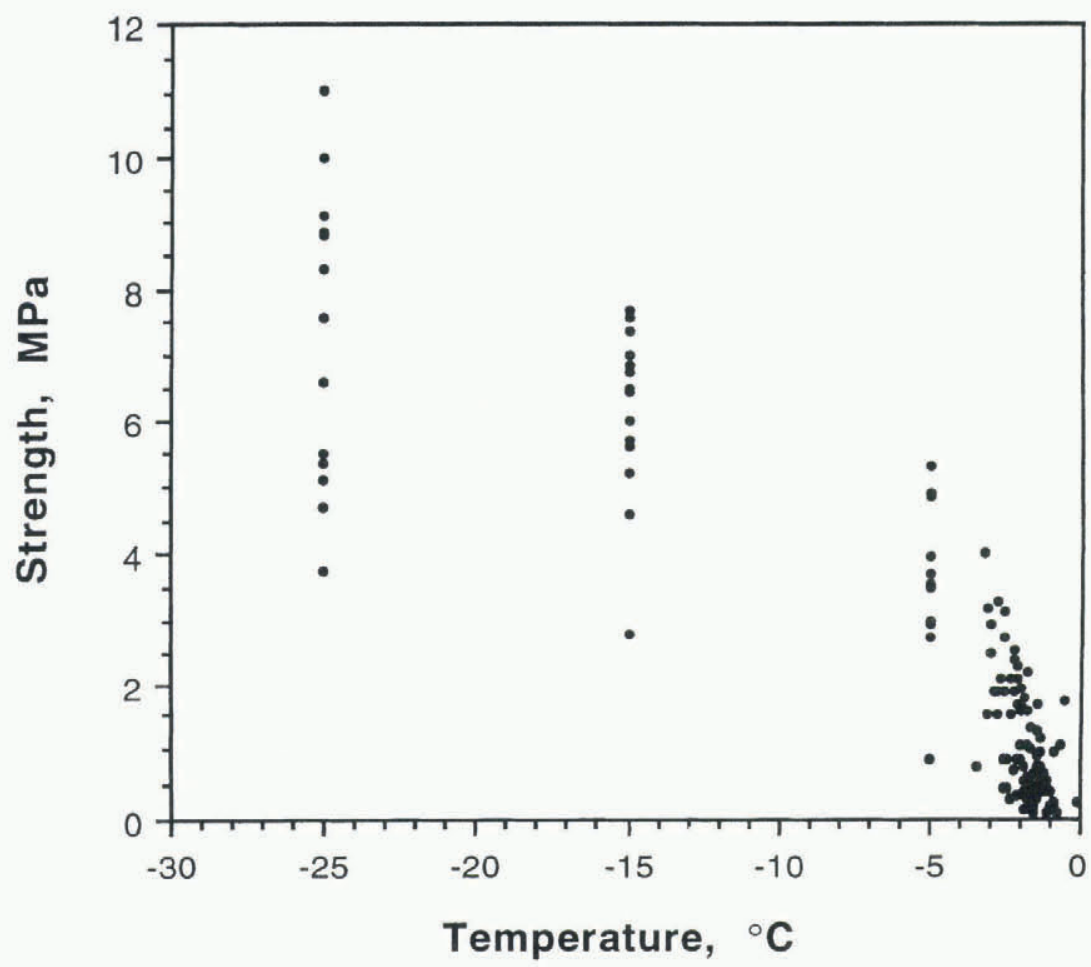

Fig. 3. The relationship between unconfined uniaxial compressive strength and temperature for field-and laboratory-tested debris-laden ice samples from Taylor Glacier. See also Table 1.

Results are presented as scattergrams of unconfined UCS against temperature for debris-laden ice (Fig. 3) and clean ice (Fig. 4). Summary data are also presented in tabular form (Table 1). The scatter of UCS at each temperature condition (Figs 3 and 4 ) reflects two sources of variability: (i) real variability due to the diversity of sample characteristics and (ii) apparent variability due to inconsistent loading conditons, as outlined above. In order to reduce the impact on any eventual conclusions of the effect of loading condition variability, emphasis is given in the following discussion to the maximum measured UCS at a given temperature, as well as to the mean

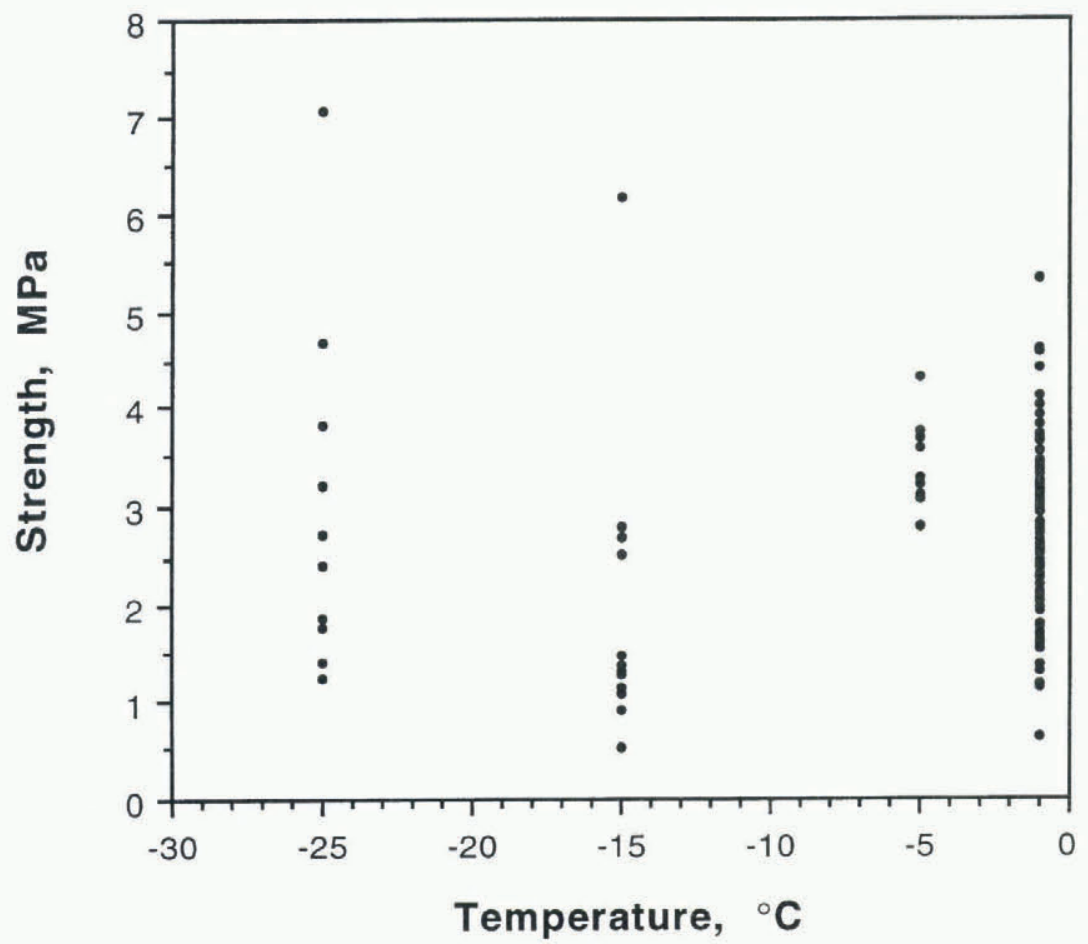

Fig. 4. The relationship between unconfined uniaxial compressize strength and lemperature for field-and laboratory-tested clean ice samples from Taylor Glacier. Note that the field-lested samples are plotted at - 1 C, although it was not possible to measure their temperatures; see text for details. See also Table 1. 
measured UCS. This approach is used because the maximum can be considered to be the data point least likely to be affected by adverse loading conditions and therefore most likely to approximate the true strength of the material. The series of maxima over a range of temperature can also be considered to define a 'strength envelope' for the variation of UCS with temperature for each ice type. This strength envelope approach to data interpretation is also employed in the geotechnical literature. The maxima series is used with appropriate caution in analysis of these results, however, because of the statistical limitation imposed by the effect of sample size. It is clear that the maximum of a sample is a function of the sample size, such that the maximum of a random sample of ten is likely to be smaller than the maximum of a random sample from the same population of 100 . The different sample sizes at different temperatures in this work (see Table 1) preclude definitive statements concerning the maxima.

\section{THE RELATIVE STRENGTHS OF GLEAN AND DEBRIS-LADEN ICE}

At the near-zero temperatures at which field tests were carried out, the mean UCS of clean ice $n=110$ experiments) was nearly 2.5 times greater than the mean UCS of debris-laden ice $(n=101$; Table 1). Similarly, the maximum UCS achieved in tests on clean ice at field temperatures (5.3 MPa; Fig. 4) was greater than the maximum UCS achieved in tests on debris-laden ice at field temperatures (4.0 MPa; Fig. 3). At progressively colder temperatures, the mean strength of the debrisladen samples increased fairly systematically as temperature decreased, with a mean UCS of $7.6 \mathrm{MPa}(n=15)$ at $-25^{\circ} \mathrm{C}$ (Table 1). In contrast, the mean UCS of clean-ice samples varied erratically with temperature, with the greatest mean UCS of clean-ice samples being 3.4 MPa $(n=10)$ at $-5^{\circ} \mathrm{C}$ (Table 1$)$.

Despite smaller sample sizes at colder temperatures (see discussion above), the maximum UCS of debris-laden ice also increased fairly systematically with decreasing temperature (maximum UCS at $-25^{\circ} \mathrm{C}$ of $11.1 \mathrm{MPa}$ ), with a lapse rate of approximately $-0.6 \mathrm{MPa}{ }^{\circ} \mathrm{C}{ }^{1}$ between $-5^{\circ}$ and $-25^{\circ} \mathrm{C}$, and a greater lapse rate at near-zero temperatures (Fig. 3). Note that the effect of sample size is such that, if sample sizes were similar at all temperatures, maxima at colder temperatures would probably be larger, and the $-5^{\circ}$ to $-25^{\circ} \mathrm{C}$ lapse rate would be greater. The maximum values of UCS of clean ice displayed an erratic pattern with temperature, unrelated to the change in the mean UCS with temperature (Fig. 4; Table 1). At both $-15^{\circ}$ and $-25^{\circ} \mathrm{C}$, the maxima were significant outliers 2.2 times and 1.5 times the next nearest UCS, respectively).

\section{QUALITATIVE ASPECTS OF THE DEFORM- ATION OF DEBRIS-LADEN ICE}

The style of deformation and mode of failure of debrisladen ice varied widely between tests and between testing conditions. Pressure melting, as indicated by the generation of turbid water during testing, occurred prolifically in all field tests, both at the platens at the sample ends and throughout the sample. Melting throughout the sample was indicated by intergranular seepage of turbid water from the sample. The quantity of pressure melting decreased significantly as temperature decreased, although a small amount of pressure melting was observed in some tests even at $-25^{\circ} \mathrm{C}$. In tests at this temperature, pressure melting occurred only at the platens and was indicated by the seeping of water from the ice/platen contact and its immediate refreezing on contact with the cold sample margins. Overall, pressure melting appeared to be a highly significant deformation mechanism enabling the accommodation of strain in debris-laden ice.

In field conditions, failure of samples occurred most frequently by the development of a cone or cones of compression with accompanying bulge. This type of failure was particularly common in samples dominated by massive (i.e. non-laminated) basal ice. In samples composed mainly of laminated basal ice, failure also occurred by the development of an axial crack or cracks (Fig. 5). In samples with a distinct layer of relatively clean basal ice, either within laminated ice or in a sample otherwise composed of massive ice, the failure of the sample was often controlled by the layer of clean ice which appeared to have a greater resistance to deformation and failure.

In progressively colder conditions, debris-laden ice

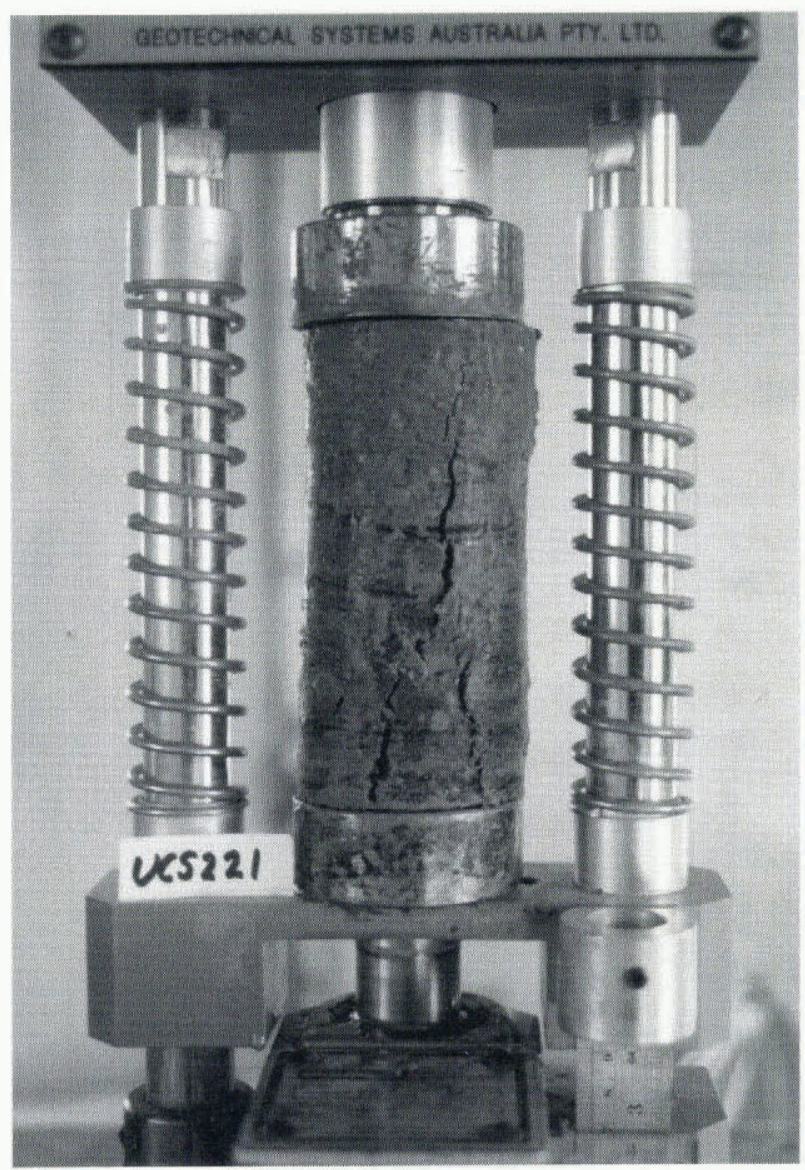

Fig. 5. A field-tested debris-laden ice sample after failure by the development of an axial crack. The lower two-thirds of this sample consist of laminated basal ice and the upper third of massive ice. Note the slight bulging evident on the righthand side of the massive part of the sample. 


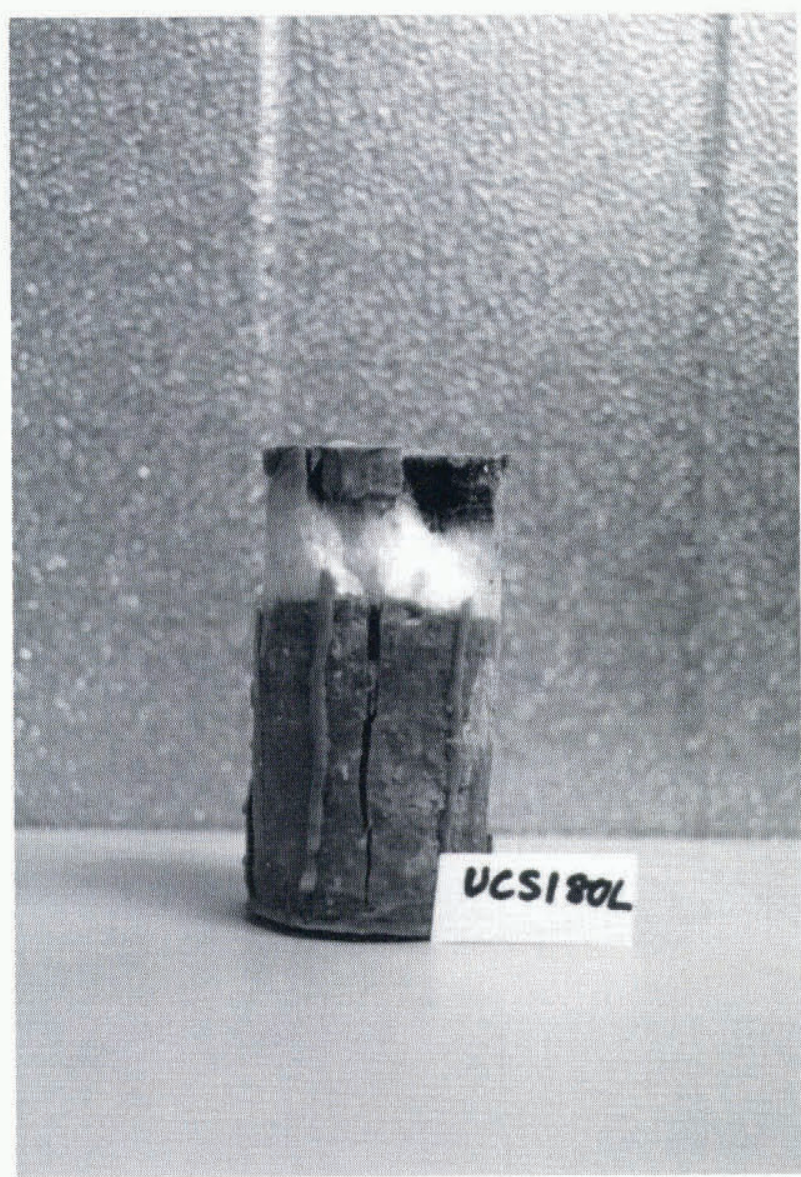

Fig. 6. A sample of laminated debris-laden basal ice after testing and failure at $-25^{\circ} \mathrm{C}$. The sample failed suddenly by the development of an axial crack. The relatively clean ice layer towards the top of the sample is opaque as a result of microcracking.

behaved in an increasingly brittle manner, with the typical mode of failure being the development of a single axial crack through the centre of the sample (Fig. 6). Although as indicated above, pressure melting occurred in some tests even at $-25^{\circ} \mathrm{C}$, failure at this temperature was generally explosive and with little deformation prior to failure. Cones of compression also developed in some tests at cold temperatures. The controlling effect of layers of clean ice within samples became less marked at colder temperatures, as the overall UCS strength of the debrisladen ice increased.

The inference that pressure melting is decreasingly important for the deformation of debris-laden ice as temperature decreases may be linked to the observation of systematically increasing strength of debris-laden ice as temperature decreases. It is possible that the increasing strength is a direct result of the changing pressure melting rate, in that as pressure melting decreases the ice becomes more resistant to deformation and stronger as a result.

\section{QUALITATIVE ASPECTS OF THE BEHAVIOUR OF GLEAN ICE}

Cracking was by far the most important deformation and failure mechanism of clean ice samples in all testing conditions. At field temperatures, the accumulation of deformation generally occurred by progressive microcracking in the initial stages of a test, with eventual failure occurring by the development of a dominant axial crack or cracks (Fig. 7). This microcracking was accompanied by decreasing translucency of samples during testing and a change in shape of the sample prior to failure. This change in shape was apparently caused by the microcracking, which despite being an inherently brittle process, resulted in a sample-scale pseudo-plasticity.

At colder temperatures, clean ice samples tended to fail very suddenly, either by explosive blocky failure or by the instantaneous and clearly audible development of a single axial crack. Microcracking was less prevalent at colder temperatures, although it did occur in some tests at $-5^{\circ}$ and $-15^{\circ} \mathrm{C}$.

The brittle behaviour of clean ice at all temperatures explains the lack of a systematic relationship between clean ice UCS and temperature. Brittle behaviour is inherently stochastic, and there is no systematic rate control exerted similar to that inferred to be exerted by pressure melting on debris-laden ice strength that would generate a systematic pattern of strength with temperature.

\section{SYNTHESIS}

Debris-laden basal ice from Taylor Glacier was weaker (in terms of UCS) than clean glacier ice from Taylor Glacier at near-zero temperatures but stronger at temperatures of $-5^{\circ} \mathrm{C}$ and colder. In fact, the UCS of debris-laden ice increased systematically with decreasing

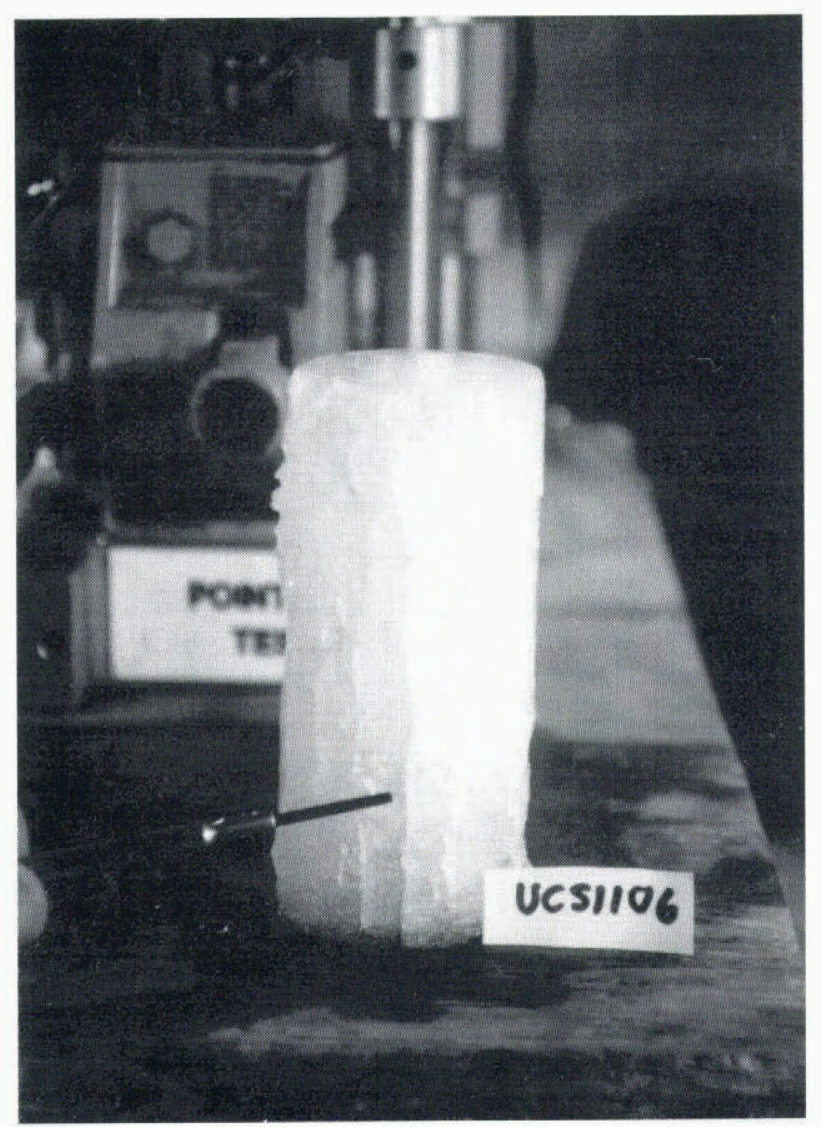

Fig. 7. A field-lested clean ice sample after failure. The screwdriver points to the axial crack which led to failure. 
temperature, whilst there were no apparent systematic relationships between strength and temperature for the clean ice. Qualitative observations of the relative behaviours of the ice types during testing suggest that this reversal in relativities may be due to the changing importance of pressure melting with temperature in the deformation of debris-laden ice. Qualitative observations also indicate that microcracking was important in the deformation of clean ice.

It is clear that the findings of this paper have no directly transferable implications for ice sheet modelling, since unconfined UCS at rapid strain rates is not a strength parameter that is likely to be an immediately useful descriptor of the behaviour of ice at the base of ice sheets. Nevertheless, the findings of this paper are extremely interesting in themselves and suggest a range of avenues for future research. In particular, work is needed in more 'glaciological' conditions (low strain rates in shear, confining stresses) to establish whether the main finding of this paper (different and changing strength relativities with temperature) and the main inference (pressure melting as the rate-controlling mechanism) are applicable to the wider mechanical behaviour of these two ice types.

The findings of this paper also help to suggest possible explanations for the apparent contradictions between various previous conclusions on the relative strengths of debris-laden and clean ice, in that temperature may be a critical parameter because of the control it is inferred to exert on pressure melting. In particular, the effect of temperature may explain the contradiction between conclusions from laboratory tests on debris-laden ice, which have usually been conducted at cold temperatures, and observations of structural features, which have generally formed at near-zero temperatures. It may be that, at colder temperatures, the rate-controlling process is the inhibition of dislocation motion by the presence of solid particles, as suggested by Hooke and others (1972).

Finally, for the purposes of illustration, let us suppose that the findings of this paper do indeed apply under glaciological conditions, and under this supposition examine the consequent implications of the presence of the debris-laden layer at the base of Taylor Glacier. Part of the bed of the central area of lower Taylor Glacier has been estimated to be at the pressure melting point, whilst other areas of the bed are probably at temperatures lower than $-20^{\circ} \mathrm{C}$ (Robinson, 1979, 1984). If, as we have supposed, the pattern of relative behaviours of clean and debris-laden ice in situ resembles the pattern of their relative behaviours in unconfined UCS testing, then the effect of the presence of a debris-bearing ice layer at the base of Taylor Glacier will be highly variable. Where and when the basal interface is cold, the presence of a basal debris-bearing layer will retard motion in the basal zone and thus the overall motion of the glacier. Where and when the interface is warm, however, the presence of a basal layer of debris-laden ice will enhance motion. It is clear, then, that the effect of the presence of a debrisbearing layer at the base of a glacier or ice sheet may be highly variable in space, and also in time, as temperature varies in space and time.

The findings of this paper are potentially highly significant for ice sheet modellers. Further work is necessary to establish the wider implications of the findings.

\section{ACKNOWLEDGEMENTS}

Many thanks are due to C. Nelson for his enthusiastic assistance at all stages of this research and in particular during the field work. This research was funded by a grant from the University of Auckland, New Zealand, and supported by the New Zealand Antarctic Programme. The support and assistance of P. Nel at the University of Auckland, and of the staff at the Crary Science and Research Laboratories, is very gratefully acknowledged. The paper has been substantially improved as a result of comments by $\mathrm{P}$. Duval and an anonymous reviewer.

\section{REFERENCES}

Beget. J. E. 1986. Modeling the influence of till rheology on the flow and profile of the Lake Michigan lobe, southern Laurentide ice sheet, U.S.A. J. Glaciol., $32(11), 235241$.

Brown, E. T., ed. 1981. Rock characterisation, testing and monitoring: ISRM suggested methods. Oxford, Pergamon.

Echelmeyer, K. and Wang Zhongxiang. 1987. Direct observation of basal sliding and deformation of basal drift at sub-freezing temperatures. J. Glaciol., 33 113), 8398.

Fisher, D. A. and R. M. Koerner, 1986. On the special rheological properties of ancient microparticle-laden Northern Hemisphere ice as derived from bore-hole and core measurements. f. Glaciol., 32 (12), $501-510$.

Hooke, R. LeB., B. B. Dahlin and M. T. Kauper. 1972. Creep of ice containing dispersed line sand. f. Glaciol., 11 63), 327-336.

Hubbard, B. and M.J. Sharp. 1995. Basal ice facies and their formation in the western Alps. Arcl. Alp. Res., 27 4), 301-310.

Lawson, W. 1989. The structural evolution of Variegated Glacier, Alaska. Ph.D. thesis, University of Cambridge.

Nickling, W. G. and L. Bennett. 1984. The shear strength characteristics of frozen coarse granular debris. J. Glaciol., 30 106), 348-357.

Reeh, N. and W.S. B. Paterson. 1988. Application of a flow model to the ice-divide region of Devon Island ice cap, Canada. f. Glaciol., $34(16), 55-63$.

Robinson, P.H. 1979. An investigation into the processes of entrainment, transportation and deposition of debris in polar ice, with special reference to the Taylor Glacier, Antarctica. (Ph.D. thesis, Victoria University of Wellington.

Robinson, P.H. 1984. Ice dynamics and thermal regime of Taylor Glacier, South Victoria Land, Antarctica. J. Glaciol., 30 105), 153 160.

Shoji, H. and C. C. Langway, Jr. 1984. Flow behavior of basal ice as related to modeling considerations. Ann. Glaciol., 5, 141-148. 